\title{
Identifikasi Life Form dan Persentase Tutupan Terumbu Karang untuk Mendukung Ketahanan Ekosistem Pantai Tiga Warna
}

\author{
Andik Isdianto $^{(1,2)}$, Oktiyas Muzaky Luthfi ${ }^{(1,2)}$, Muhammad Javier Irsyad ${ }^{(2)}$, \\ Muchamad Fairuz Haykal $^{(2)}$, Ilham Maulana Asyari ${ }^{(2)}$, Faradhilah Adibah ${ }^{(2)}$, \\ Supriyadi ${ }^{(3)}$ \\ ${ }^{1}$ Coastal Resilience and Climate Change Adaptation - Research Group \\ (CORECT), Universitas Brawijaya Malang, Indonesia \\ ${ }^{2}$ Program Studi Ilmu Kelautan, FPIK Universitas Brawijaya Malang, Indonesia \\ ${ }^{3}$ Keamanan Maritim, Universitas Pertahanan Bogor, Indonesia \\ Email: ${ }^{1}$ andik.isdianto@ub.ac.id, ${ }^{1}$ omuzakyl@ub.ac.id, \\ 2m.javierirsyad@gmail.com, ${ }^{2}$ haykalmuchamadfairuz@gmail.com, \\ 2ilhamlana60@gmail.com, ${ }^{2}$ faradhilah1998@gmail.com, \\ ${ }^{3}$ supriyadimarinescience@gmail.com
}

\section{Tersedia Online di \\ http://www.jurnal.unublitar.ac.id/i ndex.php/briliant}

\begin{tabular}{l}
\hline Sejarah Artikel \\
\hline Diterima pada 13 Agustus 2020 \\
Disetujui pada 12 November 2020 \\
Dipublikasikan pada 30 November \\
2020 \\
Hal. $808-818$
\end{tabular}

Kata Kunci:

observasi lapangan, line

intercept transect, coral foliose,

kedalaman

\section{DOI:}

http://dx.doi.org/10.28926/briliant. v3i4.537

\begin{abstract}
Abstrak: Terumbu karang merupakan ekosistem yang sangat kompleks dan memiliki peran penting bagi lingkungan di laut. Life form terumbu karang dipengaruhi oleh faktor lingkungan, salah satunya adalah kedalaman. Identifikasi life form dan pengukuran persentase tutupan karang di Pantai Tiga Warna perlu dilakukan, dengan menggunakan metode line intercept transect dan observasi lapangan. Hasil pengukuran life form di kawasan ini, baik di kedalaman 2 dan 5 meter, didominasi coral foliose. Persentase tutupan terumbu karang yaitu $43,83 \%$ yang menunjukkan bahwa kondisi ekosistem terumbu karang adalah cukup baik untuk mendukung ketahanan ekosistem di Pantai Tiga Warna.
\end{abstract}

\section{PENDAHULUAN}

Salah satu tempat wisata terumbu karang yang berada di daerah malang selatan adalah Pantai Tiga Warna yang memiliki ekosistem terumbu karang yang bagus. Pantai Tiga Warna merupakan pantai yang berada di Desa Tambakrejo Kecamatan Sumbermanjing Wetan Kabupaten Malang. Di kawasan ini merupakan kawasan MPA (marine protected area) pengunjungan hanya dibatasi 100 orang per hari. Di Pantai Tiga Warna ini terdapat ekosistem terumbu karang yang sangat bagus diantara pantai-pantai yang ada di sekiarnya. Terumbu karang merupakan ekosistem yang dibangun oleh biota laut penghasil kapur, terutama oleh hewan karang, bersama-sama dengan biota lain yang hidup di dasar laut maupun kolom air. Hewan karang, yang merupakan penyusun utama terumbu karang, terdiri dari polip dan skeleton (Giyanto et al., 2017). 
Karang adalah hewan yang dikenal sebagai polip yang termasuk dalam filum Cnidaria ordo scleractinia. Dalam bentuk sederhananya karang dapat terdiri dari satu polip saja, dalam banyak spesies karang, individu karang berkembang menjadi banyak individu yang disebut dengan koloni. Setiap polip seperti kantung berserat dengan cincin tentakel yang melindungi mulutnya, dan tampak seperti anemon kecil. Kumpulan hewan karang yang bersimbiosis dengan zooxanthella yang membentuk suatu ekosistem disebut sebagai terumbu karang (Reskiwati et al., 2018). Terumbu karang merupakan ekosistem yang sangat kompleks dan memiliki peran penting untuk lingkungan dan bagi kelangsungan hidup di laut. Secara ekologis terumbu karang ini mejadi tempat untuk mencari makan ikan (feeding grounds), berkembang biak (breeding grounds), mengasuh (nursery grounds) dan tempat berlindung dari berbagai jenis ikan dan invertebrata lain (Candri et al., 2019). Ekosistem Terumbu karang dan segala kehidupan yang terdapat di dalamnya merupakan salah satu kekayaan alam yang bernilai tinggi. Manfaat dari terumbu karang ini sangat berdampak pada masyarakat dan lingkungan yang ada disekitar dan dampaknya sangat berhubungan satu sama lain (Salim, 2012).

Manfaat terumbu karang dapat diidentifikasi menjadi dua, yaitu manfaat langsung dan manfaat tidak langsung. Manfaat terumbu karang yang langsung dapat dinikmati oleh manusia adalah pemanfaatan sumber daya ikan, batu karang, pariwisata, penelitian dan pemanfaatan biota perairan lainnya. Manfaat terumbu karang yang tidak langsung adalah terumbu karang sebagai penahan abrasi pantai, keanekaragaman hayati, tempat berlangsungnya siklus biologi, kimiawi, dan fisik secara global yang mempunyai tingkat produktivitas yang sangat tinggi, penyedia lahan dan tempat budidaya berbagai hasil laut, tempat berlindung, pemijahan, berkembangbiak dan juga tempat untuk mencari makan biota yang ada di sekitarnya (Muhlis, 2011).

Faktor lingkungan akan berpengaruh pada terumbu karang seperti sedimentasi akan menghambat zooxanthellae untuk fotosintesis yang akan menghambat pertumbuhan karang (Luthfi et al., 2017). Arus juga berpengaruh pada terumbu karang. Arus dapat membawa sedimen yang berada di permukaan maupun yang berada di dasar perairan dan mempengaruhi sedimentasi (Supriyadi et al., 2017). Gangguan kesehatan juga salah satu ancaman kesehatan karang yang disebabkan oleh faktor lingkungan dan pesaing bentik. Gangguan kesehatan adalah faktor potensial untuk kematian karang selain penyakit karang. Kesehatan yang terganggu juga mempengaruhi tingkat pertumbuhan karang dan mengancam kesehatan karang. Gangguan kesehatan juga memiliki peran dalam menginduksi penyakit karang (Luthfi et al., 2018).

Bentuk pertumbuhan karang (coral life form) dibedakan menjadi Acropora dan non Acropora, dengan perbedaan morfologi berupa tipe bercabang (branching), tipe padat (massive), tipe merayap (encrusting), tipe daun (foliose), tipe meja (tabulate), serta tipe jamur (mushroom). Pada suatu perairan terumbu karang bisa dapat didominasi oleh satu bentuk pertumbuhan berdasarkan faktor lingkungan tersendiri (Saptarini et al., 2016). Life form terumbu karang sangat dipengaruhi oleh faktor lingkungan salah satunya adalah kedalaman. Menurut (Setiady \& Usman, 2018) Kedalaman akan berpengaruh pada intensitas cahaya matahari yang masuk ke perairan sementara itu cahaya sangat berpengaruh untuk fotosintesispembentuk terumbu karang. Berdasarkan data kedalaman dasar laut, terumbu karang dapat hidup dan terkena sinar matahari sampai kedalaman $20 \mathrm{~m}$. Lebih dari kedalaman 20 meter maka terumbu karang tidak akan bertahan untuk hidup, karena terumbu karang memiliki ketahanan hidup yang cukup rendah dan bertumbuh dengan kualitas ekosistem yang memiliki syarat khusus. 
Ketahanan ekosistem adalah kemampuan suatu ekosistem untuk mendapat gangguan dan kembali pulih ke keadaan normal tanpa merubah fungsi semula. Ekosistem dianggap tangguh jika bisa beradaptasi mengubah dan mempertahankan status aktif yang stabil. Ekosistem yang tangguh sangat penting untuk pengurangan resiko bencana komunitas pesisir (Islam et al., 2020). Ketahanan ekosistem terumbu karang sangat penting untuk menunjang kehidupan biota yang ada di wilayah Pantai Tiga Warna, karena terumbu karang sendiri memiliki peranan penting di ekosistem pesisir. Pantai Tiga Warna memiliki terumbu karang yang memiliki fungsi yang baik dalam menunjang ekosistem sekitarnya dan menjadi bagian yang penting dari ekosistem tersebut. Namun, belum pernah ada penelitian tentang identifikasi life form dan pengukuran persentase tutupan karang tersebut. Penelitian ini bertujuan untuk mengetahui jenis life form dan tingkat persentase tutupan karang di Pantai Tiga Warna untuk menunjang ketahanan ekosistem di wilayah tersebut.

\section{METODE}

Data sekunder didapatkan dari studi literatur dan laporan dari lembaga setempat, dan pengumpulan data primer dilakukan dengan metode LIT (Line Intercept Transect) untuk mengambil data terumbu karang. Metode LIT adalah metode dengan menggunakan transek garis lurus secara horizontal lalu dicatat substrat yang berada pada transek tersebut. Menurut (Sarbini et al., 2016), keuntungan dari metode ini adalah memerlukan sedikit peralatan, relatif sederhana dalam penerapannya, dan merupakan teknik yang akurat serta efisien untuk mendapatkan data kuantitatif tentang tutupan karang. Metode ini memerlukan orang yang berpengalaman dan ahli penyelaman karena tingkat kesukaran tinggi dalam pengambilan data di dasar perairan, dikarenakan kuatnya arus dan gelombang.

Menurut (Octriviana et al., 2017), metode observasi lapang dilakukan dengan memberikan gambaran dan analisa terhadap objek yang diteliti (observasi) yang telah terjadi di lapang. Alat dan bahan pada saat melakukan penelitian adalah sabak dan pensil untuk pencatatan data, alat selam untuk melakukan pengambilan data, roll meter untuk mengetahui panjang tutupan substrat dan terakhir patok untuk menancapkan roll meter sebagai metode LIT. Tambakrejo, Sumbermanjing, Malang, Jawa Timur. Terdapat 2 stasiun pengamatan, antara lain :

1. Stasiun 1 memiliki kedalaman 2 meter

2. Stasiun 2 memiliki kedalaman 5 meter

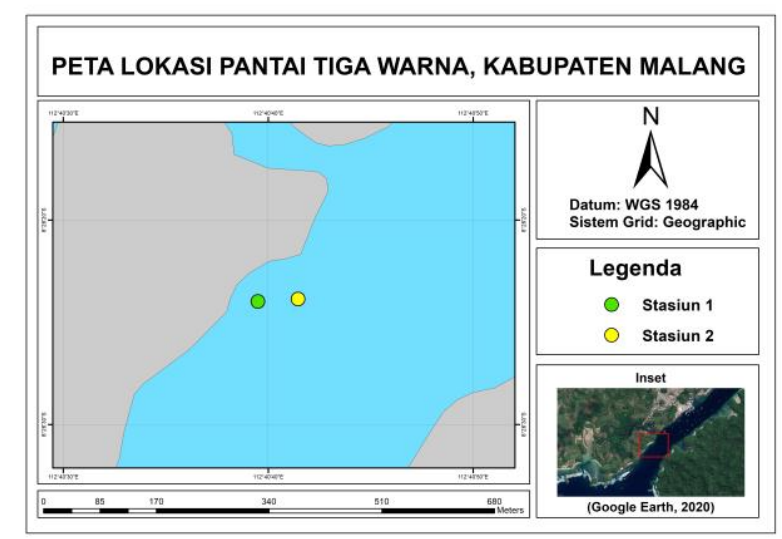

Gambar 1. Peta Lokasi Penelitian

Data sekunder merupakan data yang telah dikumpulkan oleh lembaga pengumpulan data dan dipublikasikan kepada masyarakat pengguna data, maka dari itu penggunaan data sekunder adalah hal yang sangat berguna (Erlina, 2008). Data sekunder didapat dari

810 BRILIANT: Jurnal Riset dan Konseptual Volume 5 Nomor 4, November 2020 
orang yang sudah melakukan penelitian dari sumber yang telah ada dan digunakan untuk mendukung informasi primer yang diperoleh. Data sekunder ini berupa studi literatur, dokumentasi, dan lainnya. Pengumpulan data primer adalah data yang didapatkan di lapang. Dalam memperoleh data primer dapat melakukan observasi dan pengambilan data lapang secara langsung. Metode observasi merupakan teknik pengumpulan data secara sistematis. Peneliti melakukan pengamatan dan pencatatan terhadap gejala dan fenomena yang akan diselidiki (Marzuki, 1986). Pada penelitian ini observasi yang dilakukan pada pengamatan ini adalah observasi lapang yang dilakukan sebagai metode pengamatan untuk pembantu dengan tujuan untuk mengetahui kondisi lapang.

Untuk menetukan jenis life form dan tutpan terumbu karang kita memakai metode LIT (Line Intercept Transect). Menurut (Wahib et al., 2019) Line Intercept Transect (LIT) merupakan metode yang digunakan dalam survei monitoring terumbu karang. Metode Line Intercept Transect dikembangkan oleh Australian Institute of Marine Science (AIMS) dan The Great Barrier Reef Marine Park Authority (GBRMPA). Line Intercept Transect merupakan metode monitoring dengan cara menarik garis lurus menggunakan transek roll meter dan melakukan pencatatan jenis life form dan ukuran tutupan substrat di transek tersebut. Pada metode LIT ini kami memakai panjang transek berjarak 30 meter di 2 stasiun, dengan asumsi Pantai Tiga Warna yang tidak begitu luas, maka jarak 30 meter di 2 stasiun dianggap sudah merepresentasikan wilayah tersebut.

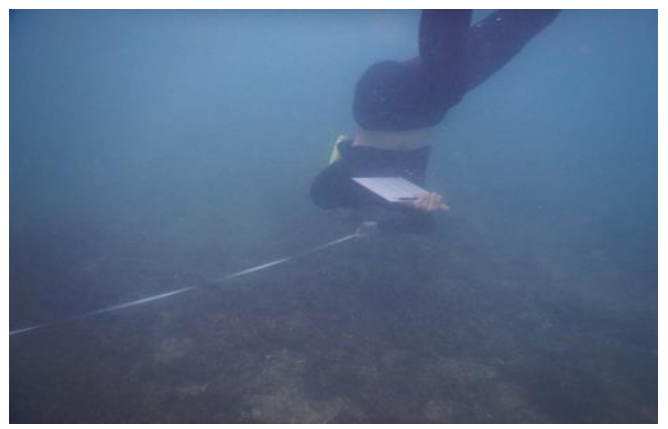

Gambar 2. Pengambilan Data Menggunakan Metode LIT (Line Intercept)

Dalam penelitian ini kami menggunakan protokol Australian Institute of Marine Science (AIMS), adalah badan penelitian kelautan tropis Australia. AIMS memainkan peran penting dalam menyediakan penelitian skala besar, jangka panjang, dan kelas dunia yang membantu pemerintah, industri, dan komunitas yang lebih luas untuk membuat keputusan yang tepat tentang pengelolaan kawasan laut Australia. AIMS didirikan pada tahun 1972, bertindak selaku explorer di tahuntahun awalnya, mendefinisikan Great Barrier Reef dan keanekaragaman hayatinya, serta memperkenalkan ekosistem laut yang luar biasa di Australia utara kepada orang Australia. Dalam 20 tahun terakhir, fokus AIMS telah beralih ke pemantauan dan pemahaman perubahan dalam ekosistem ini, dari Scott Reef Australia Barat hingga perairan pesisir Darwin dan Great Barrier Reef. Dekade berikutnya akan menjadi salah satu tindakan, membantu mempertahankan dan memperbaiki ekosistem ini dalam menghadapi perubahan iklim (AIMS, 2020).

Menurut (English et al., 1998) rumus persentase tutupan terumbu karang adalah membandingkan ukuran tutpan substrat dengan panjang garis transek menggunakan persamaan berikut:

$L=\frac{L i}{N} \times 100$ 
Keterangan:

L : persentase tutupan

Li : total panjang life form

$\mathrm{N} \quad$ : panjang transek

\section{HASIL}

Kondisi perairan pada stasiun 1 ini memiliki kedalaman 2 meter dan perairannya tidak keruh. Tingkat intensitas cahaya di stasiun 1 sangat tinggi, cahaya yang masuk bisa sampai ke dasar perairan. Kondisi perairan pada stasiun 2 ini memiliki kedalaman 5 meter dan perairannya tidak keruh. Tingkat intensitas cahaya di stasiun 2 sangat tinggi, cahaya yang masuk bisa sampai ke dasar perairan. Menurut (Infopondokdadap, 2018), terumbu karang pada Pantai Tiga Warna tersebar pada kedalaman $2-8$ meter dimana terdapat terumbu karang berukuran besar. Intensitas cahaya di Pantai Tiga Warna sangat tinggi dan suhu rata-rata $25^{\circ} \mathrm{C}$, dan keadaan perairan berarus pelan. Pada stasiun 1 dan stasiun 2 didapatkan grafik persentase tutupan substrat sebagai berikut:

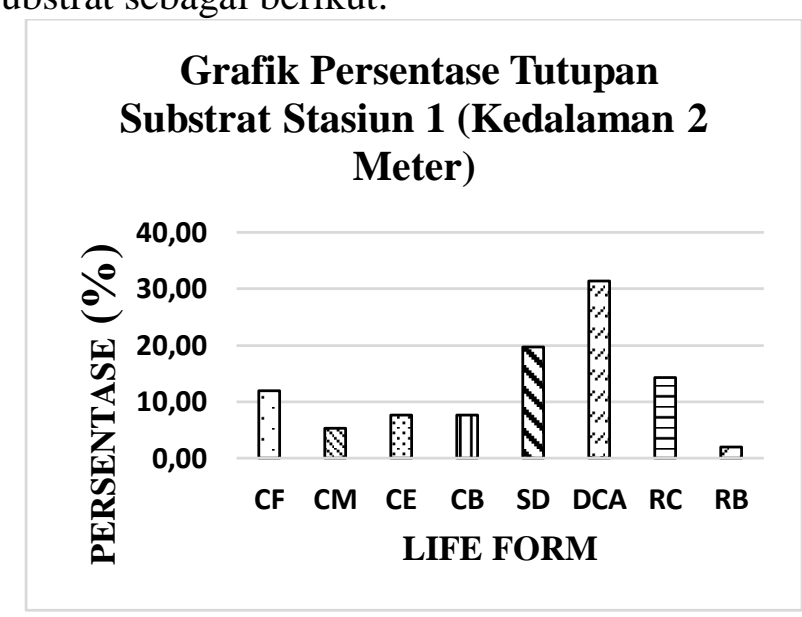

Gambar 3. Grafik Tuptupan Substart Stasiun 1

Dapat dilihat ada grafik persentase tutupan substrat Pada stasiun 1 terdapat 4 jenis life form karang yaitu CF (Coral Foliose), CM (Coral Massive), CE (Coral Encrusting), CB (Coral Branching) dan tutupan subsrat yang bukan karang di stasiun 1 yaitu SD (Sand), DCA (Dead Coral With Algae), RC (Rock), RB (Rubish). Persentase yang paling tinggi di staiun 1 adalah DCA (Dead Coral With Algae) dan yang paling rendah adalah RB (Rubbish).

812 BRILIANT: Jurnal Riset dan Konseptual Volume 5 Nomor 4, November 2020 


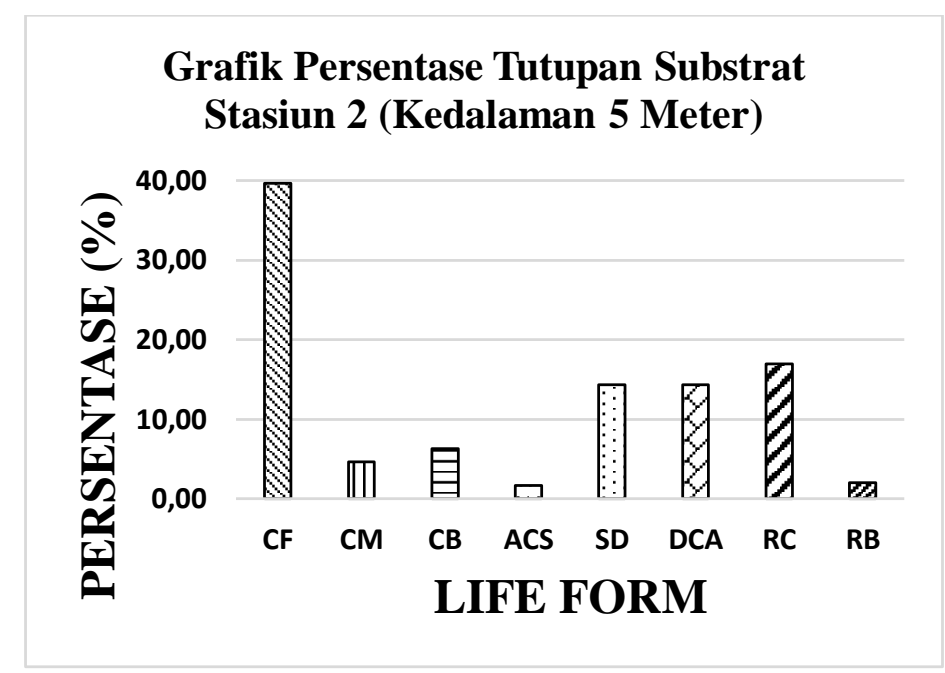

Gambar 4. Grafik Tutupan Substart Stasiun 2

Dapat dilihat ada grafik persentase tutupan substrat Pada stasiun 2 terdapat 4 jenis life form karang yaitu CF (Coral Foliose), CM (Coral Massive), CB (Coral Branching), ACS (Acropora Sub-Massive). Dan untuk tutupan subsrat yang bukan karang di stasiun 2 yaitu SD (sand), DCA (Dead Coral With Algae), RC (Rock), RB (Rubish) Dapat dilihat ada grafik persentase tutupan substrat yang paling tinggi di staiun 2 adalah CF (Coral Foliose) dan yang paling rendah adalah RB (Rubbish). Pada stasiun 1 dan stasiun 2 didapat jenis life form terumbu karang sebagai berikut :

Tabel 1. Jenis Life Form Terumbu

\begin{tabular}{|c|c|c|c|c|}
\hline \multirow{2}{*}{$\begin{array}{c}\text { Life } \\
\text { Form }\end{array}$} & \multicolumn{2}{|c|}{ Stasiun 1 (Kedalaman 2 Meter) } & \multicolumn{2}{c|}{ Stasiun 2 (Kedalaman 5 Meter) } \\
\cline { 2 - 5 } & $\begin{array}{c}\text { Panjang Total } \\
(\mathrm{M})\end{array}$ & Persentase (\%) & $\begin{array}{c}\text { Panjang Total } \\
(\mathrm{M})\end{array}$ & Persentase (\%) \\
\hline CF & 3,6 & 12,00 & 11,9 & 39,67 \\
\hline CM & 1,6 & 5,33 & 1,4 & 4,67 \\
\hline CE & 2,3 & 7,67 & 1,9 & 6,33 \\
\hline CB & 2,3 & 7,67 & 0,5 & 1,67 \\
\hline
\end{tabular}

Pada hasil tersebut sebaran life form pada stasiun 1 di kedalaman 2 meter terdapat terdapat 4 jenis life form karang yaitu CF (coral foliose), CM (Coral Massive), CE (Coral Encrusting), CB (Coral Branching) dan Persentase terbesar didominasi oleh Life Form Coral Foliose sebesar 12,00\% dan persentase terkecil didominasi oleh Life Form Coral Massive sebesar 5,33\%. Pada stasiun 2 di kedalaman 5 meter terdapat 4 jenis life form karang yaitu CF (Coral Foliose), CM (Coral Massive), CB (Coral Branching), ACS (Acropora Sub-Massive). Persentase terbesar didominasi oleh Life Form Coral Foliose sebesar 39,67\% dan persentase terkecil didominasi oleh Life Form Acropora Sub-Massive sebesar $1,67 \%$.

Jenis life form yang paling dominan di wilayah Pantai Tiga Warna pada kedalaman 2 dan 5 meter adalah Coral Foliose. Hal ini dikarenakan tingkat kekeruhan yang rendah dan intensitas cahaya yang tinggi memungkinkan Coral Fioliose tumbuh luas di lingkungan Pantai Tiga Warna. Menurut (Barus et al., 
2018), Coral Foliose ditemukan pada daerah yang memiliki tingkat kekeruhan rendah dan memiliki intensitas cahaya yang sangat tinggi. Untuk persentase tutupan terumbu karang pada kedua stasiun adalah sebagai berikut:

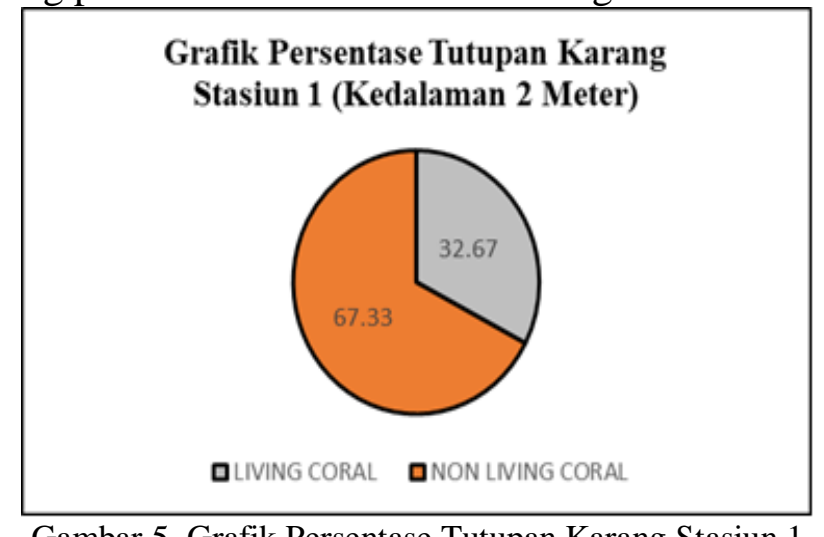

Gambar 5. Grafik Persentase Tutupan Karang Stasiun 1

Tingkat tutupan karang menurut (Zamani \& Madduppa, 2011) ialah 0 $25 \%$ digolongkan buruk, $25-50 \%$ digolongkan sedang, $50-75 \%$ digolongkan baik, dan $75-100 \%$ digolongkan sangat baik. Pada stasiun 1 persentase tutupan karang yaitu sebesar 35,33 \% dan persentase substrat yang bukan karang yaitu 64,67\%. dari data tersebut menandakan kategori persentase tutupan karang di stasiun 1 tergolong sedang.

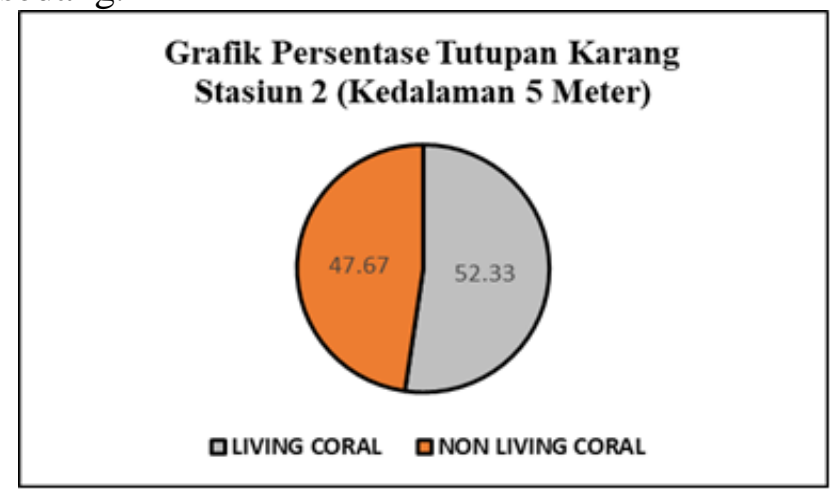

Gambar 6. Grafik Persentase Tutupan Karang Stasiun 2

Tingkat tutupan karang menurut (Zamani \& Madduppa, 2011) ialah 0 $25 \%$ digolongkan buruk, 25 - 50\% digolongkan sedang, $50-75 \%$ digolongkan baik, dan $75-100 \%$ digolongkan sangat baik. Pada stasiun 2 tingkat tutupan karang yaitu sebesar 52,33\% dan tingkat tutupan substrat yang bukan karang sebesar $47,67 \%$. dari data tersebut menandakan kategori tutupan karang di stasiun 2 tergolong baik. Dilihat dari grafik diatas persentase tutupan karang di stasiun 1 sebesar 35,33\% dan persentase di stasiun 2 sebesar 53,33\% . Jika dirata-ratakan maka persentase tutupan terumbu karang di Pantai Tiga Warna yaitu sebesar 43,83\% yang menandakan kategori tutupan karang di Pantai Tiga Warna tergolong sedang. Kategori sedang diklasifikasikan berdasarkan Gomez \& Yap(1988), bahwa persentase tutupan karang 25 - 49,9\% termasuk ke dalam kategori sedang. Teori tersebut dijadikan acuan Coral Reef Information And Training Centers (CRITC) - COREMAP LIPI dalam mennetukan status persentase tutupan karang di Indonesia. 
Dalam ketahanan ekosistem, terumbu karang sangat berperan penting bagi kehidupan di laut. Terumbu karang berperan dalam melindungi pantai dari hantaman ombak dan arus yang kuat, terumbu karang juga berfungsi sebagai habitat, tempat mencari makan, tempat perawatan dan pemijahan biota laut (Arini, 2013). Hilangnya terumbu karang dapat mengakibatkan terganggunya fungsi ekologis penting, tidak hanya hilangnya habitat tetapi juga hilangnya perlindungan pulau akibat dampak kenaikan permukaan laut. Jika tidak terdapat karang berbatu yang menghasilkan sedimen batu gamping, maka fungsi terumbu karang sebagai pemecah gelombang akan berkurang karena perairannya semakin dalam sehingga abrasi pantai lambat laun akan semakin meningkat (Suryanti et al., 2011).

Ketahanan ekosistem dapat dicirikan sebagai kapasitas untuk memelihara penyediaan barang dan jasa ekosistem. Untuk terumbu karang, hal ini berarti kemampuan ekosistem untuk mempertahankan dominasi karang, kompleksitas struktur (habitat) yang memadai, dan laju pertumbuhan terumbu yang positif. Sistem terumbu dengan ketahanan rendah akan segera kehilangan tutupan karang, mengurangi kualitas habitat, dan mengalami erosi. Faktor-faktor yang mendukung ketahanan ekosistem terumbu karang secara garis besar dapat dikelompokkan menjadi 4 kategori: kondisi ekosistem; keanekaragaman hayati; konektivitas antar wilayah; dan kondisi lingkungan setempat (Schuttenberg \& Marshall, 2005).

Faktor ketahanan meningkatkan kapasitas komunitas terumbu karang untuk pulih setelah peristiwa kematian. Mereka beroperasi dengan meningkatkan regenerasi terumbu melalui rekolonisasi dan pertumbuhan kembali. Faktor ketahanan terbagi dalam dua kategori besar. Faktor intrinsik adalah faktor yang ditentukan oleh karakteristik ekologi komunitas terumbu karang tertentu, seperti kemampuan bawaan dari berbagai karang untuk menghasilkan larva yang akan berhasil direkrutmen. Faktor ekstrinsik adalah karakteristik fisik yang membuat terumbu lebih atau kurang mungkin menerima larva pada arus yang ada atau yang mendukung penyelesaian dan perekrutan larva yang berhasil (West \& Salm, 2003). Dari data yang diperoleh, jenis life form karang yang mampu menahan gelombang dan arus adalah coral massive dan acropora sub-massive. coral massive kebanyakan tumbuh di perairan berarus deras dan karang acropora biasanya tumbuh di daerah di mana gelombang pecah dan karang ini dapat bertahan dengan arus dan gelombang yang menuju ke pantai (Zamani et al., 2011). Jenis life form yang mendominasi pada Pantai Tiga Warna adalah coral foliose, jenis ini memiliki laju pertumbuhan $4,7 \mathrm{~cm}^{2} /$ bulan (Luthfi \& Nurmalasari, 2013). Dominansi coral foliose pada perairan Pantai Tiga Warna menunjukkan bahwa kondisi perairan tersebut memiliki tingkat kejernihan yang baik, dan memiliki intensitas cahaya yang baik (Barus et al., 2018). Dominansi dari life form coral foliose, coral branching, coral massive, dan Acropora Sub-massive dapat menjadi tolak ukur bahwa kondisi perairan di Pantai Tiga Warna dalam kondisi baik, dan menunjukkan keberadaan terumbu karang dapat meningkatkan keanekaragaman hayati di Pantai Tiga Warna, serta dapat menjadi indikator kondisi fisik ekologi terumbu karang pada Pantai Tiga Warna tergolong baik. Kondisi tersebut menjadi suatu indikator kesehatan ekosistem, yang dapat menjadi faktor pendukung dalam peningkatan keanekaragaman hayati dan juga ketahanan ekosistem berkelanjutan yang mendukung ketahanan ekosistem di Pantai Tiga Warna. 


\section{KESIMPULAN}

Jenis life form di Pantai Tiga Warna adalah CF (Coral Foliose), CM (Karang Masif), CB (Coral Branching), ACS (Acropora Sub-Massive) dan CE (Coral Encrusting). Life form yang paling dominan di kawasan Pantai Tiga Warna pada kedalaman 2 dan 5 meter adalah Coral Foliose. Hal ini dikarenakan rendahnya tingkat kekeruhan dan intensitas cahaya yang tinggi memungkinkan tumbuhan Coral Foliose tumbuh di lingkungan PantaiTiga Warna. Untuk tingkat ketahanan ekosistem Pantai Tiga Warna dapat dilihat dari persentase tutupan terumbu karang di Pantai Tiga Warna yaitu sebesar 43,83\%, yang menunjukkan bahwa kondisi ekosistem terumbu karang adalah cukup baik untuk mendukung ketahanan ekosistem di Pantai Tiga Warna.

\section{SARAN}

Ekosistem terumbu karang pada Pantai Tiga Warna memiliki potensial yang tinggi. Dibutuhkan penelitian dan pengawasan berkelanjutan untuk menjaga biodiversitas dan ketahanan terumbu karang yang ada pada Pantai Tiga Warna. Serta pengurangan aktifitas manusia juga dapat menjadi faktor penunjang dalam mempertahankan ekosistem Terumbu Karang. Ekosistem Terumbu Karang merupakan ekosistem yang kompleks, yang sangat terpengaruhi oleh perubahan kualitas perairan. Sehingga diperlukan adanya identifikasi kualitas perairan pada ekosistem terumbu karang terhadap pengamatan kondisi lingkungan dengan tujuan mengukur daya dukung ekosistem terumbu karang terhadap ketahanan pesisir Pantai Tiga Warna.

\section{DAFTAR RUJUKAN}

AIMS. (2020). About AIMS.

Arini, D. I. D. (2013). Potensi Terumbu Karang Indonesia; Tantangan dan Upaya Konservasinya. Info Balai Penelitian Kehutanan, 3(2), 147-172.

Barus, B. S., Prartono, T., \& Soedarma, D. (2018). Pengaruh Lingkungan Terhadap Bentuk Pertumbuhan Terumbu Karang Di Perairan Teluk Lampung. Jurnal Ilmu Dan Teknologi Kelautan Tropis, 10(3), 699-709. https://doi.org/10.29244/jitkt.v10i3.21516

Candri, D. A., Ahyadi, H., Riandinata, S. K., \& Virgota, A. (2019). Analisis Persentase Tutupan Terumbu Karang Gili Tangkong, Sekotong Kabupaten Lombok Barat. BioWallacea, 5(1), 29-35. https://doi.org/10.29303/biowal.v5i1.106

English, S., Wilkinson, C., \& Baker, V. (1998). Survey manual for tropical marine resources. (2nd ed.). Australian Institute Of Marine Science.

Erlina. (2008). Metode Penelitian Bisnis Akuntansi dan Manajemen Edisi Kedua. USU Press.

Giyanto, Abrar, M., Hadi, T. A., Budiyanto, A., Hafizt, M., Salatalohy, A., \& Iswari, M. yulia. (2017). Status Terumbu Karang Di Indonesia 2017 (Suharsono (ed.)). CoreMap - CTI. http://www.oseanografi.lipi.go.id

Gomez, E. D., \& Yap, H. T. (1988). Monitoring reef condition In : R.A. Kenchington \& B.E.T. Hudson (eds). In Coral Reef Management Handbook (pp. 187-195). UNESCO. 
Infopondokdadap. (2018). Laporan Monitoring Ekosistem Terumbu Karang Pantai Tiga Warna.

Islam, M. A., Paull, D. J., Griffin, A. L., \& Murshed, S. (2020). Assessing ecosystem resilience to a tropical cyclone based on ecosystem service supply proficiency using geospatial techniques and social responses in coastal Bangladesh. International Journal of Disaster Risk Reduction, 49(November 2019), 101667. https://doi.org/10.1016/j.ijdrr.2020.101667

Luthfi, O. M., Agung, R. M., \& Sontodipoero, M. R. (2017). Skeleton microstructure of Porites lutea in Skeleton Microstructure of Porites lutea in Kondang Merak ,Malang, East Java. AIP Conference Proceedings, 030009(November).

Luthfi, O. M., \& Nurmalasari, N. (2013). Pertumbuhan Karang Foliose (Daun) Leptoseris yabei pada Taman Karang di Cagar Alam Pulau Sempu, Malang. Seminar Nasional Perikanan V, 452-457.

Luthfi, O. M., Rosyid, A., Isdianto, A., Jauhari, A., \& Setyohadi, D. (2018). The compromised health of coral at South Java Sea: Study area Prigi Bay The Compromised Health of Coral at South Java Sea : Study Area Prigi Bay. AIP Conference Proceedings, 050007(October 2018).

Marzuki. (1986). Metode Riset. FE-UII.

Muhlis. (2011). Ekosistem terumbu karang dan kondisi oseanografi perairan kawasan wisata bahari lombok. Berk. Penel. Hayati, 16.

Octriviana, R., Ainnurasjid, \& Ardiarini, R. (2017). Observasi Plasma Nutfah Bambu Di Kabupaten Malang. Jurnal Produksi Tanaman, 5(6), 1044-1052.

Reskiwati, Lalamentik, L., \& Rembet, U. (2018). Studi Taksonomi Karang Genus Favia (Oken, 1815) Di Rataan Terumbu Perairan Desa Kampung Ambong Kecamatan Likupang Timur Minahasa Utara. Jurnal Ilmiah Platax, 6(1), 188-193.

Salim, D. (2012). Pengelolaan Ekosistem Terumbu Karang Akibat Pemutihan (Bleaching) Dan Rusak. Jurnal Kelautan, 5(2), 1907-9931. https://doi.org/10.1016/j.stemcr.2014.03.011

Saptarini, D., Mukhtasor, \& Rumengan, I. F. M. (2016). Variasi Bentuk Pertumbuhan (lifeform) Karang di Sekitar Kegiatan Pembangkit Listrik, Studi Kasus Kawasan Perairan PLTU Paiton, Jawa Timur. Seminar Nasional Biodiversitas, 5(2), 1-9.

Sarbini, R., Kuslani, H., \& Nugraha, Y. (2016). Teknik pengamatan tutupan terumbu karang dengan menggunakan transek garis (line intercept transect) di Pulau Kumbang Kepulauan Karimun Jawa. Buletin Teknik Litkayasa, 14(1), 33-42.

Schuttenberg, H., \& Marshall, P. (2005). Managing for Mass Coral Bleaching Strategies for Supporting Socio-ecological Resilience. Status of Coral Reefs in the Carribean after Bleaching and Hurricanes of 2005, 125-137.

Setiady, D., \& Usman, E. (2018). Terumbu Karang Berdasarkan Kedalaman Laut dan Pengaruh Sedimen Perairan Kepulauan Aruah, Kabupaten Rokan Hilir, Provinsi Riau. Jurnal Lingkungan Dan Bencana Geologi, 9(1), 21-30.

Supriyadi, Hidayati, N., \& Isdianto, A. (2017). Analisis Sirkulasi Arus Laut Permukaan Dan Sebaran Sedimen. Prosiding Seminar Nasional Kelautan Dan Perikanan III, September, 175-181. 
Suryanti, Supriharyono, \& Indrawan, W. (2011). Kondisi Terumbu Karang dengan Indikator Ikan Chaetodontidae di Pulau Sambangan Kepulauan Karimun Jawa, Jepara, Jawa Tengah. Buletin Oseanografi Marina, 1.

Wahib, N. K., Kelautan, I., Brawijaya, U., \& Malang, K. (2019). Kajian Efektivitas Penggunaan Metode LIT, PIT, dan QT Untuk Monitoring Tutupan Substrat.

West, J. M., \& Salm, R. V. (2003). Resistance and Resilience to Coral Bleaching: Implications for Coral Reef Conservation and Management. Conservation Biology, 17(4), 956-967. https://doi.org/10.1046/j.1523-1739.2003.02055.x

Zamani, N. P., \& Madduppa, H. H. (2011). A Standard Criteria for Assesing the Health of Coral Reefs: Implication for Management and Conservation. Journal of Indonesia Coral Reefs, 1(2), 137-146.

Zamani, N. P., Wardiatno, Y., \& Nggajo, R. (2011). Strategi Pengembangan Pengelolaan Sumberdaya Ikan Ekor Kuning (Caesio Cuning) Pada Ekosistem Terumbu Karang Di Kepulauan Seribu Development. Jurnal Saintek Perikanan, 6(2), 38-51. 